\title{
Leukotriene Signaling in Atherosclerosis and Ischemia
}

\author{
Magnus Bäck
}

Published online: 24 October 2008

(C) The Author(s) 2009. This article is published with open access at Springerlink.com

\begin{abstract}
Introduction The inflammatory process of atherosclerosis is associated with several pathophysiological reactions within the vascular wall. The arachidonic acid released by phospholipase $\mathrm{A}_{2}$ serves as substrate for the production of a group of lipid mediators known as the leukotrienes, which induce pro-inflammatory signaling through activation of specific BLT and CysLT receptors.

Discussion Leukotriene signaling has been implicated in early lipid retention and foam cell accumulation, as well as in the development of intimal hyperplasia and advanced atherosclerotic lesions. Furthermore, the association of leukotrienes with degradation of extracellular matrix has suggested a role in atherosclerotic plaque rupture. Finally, studies of either myocardial or cerebral ischemia and reperfusion indicate that leukotriene signaling in addition may be involved in the development of ischemic injury. Conclusion Both leukotriene synthesis inhibitors and leukotriene receptor antagonists have been suggested to induce beneficial effects at different stages of the atherosclerosis process.
\end{abstract}

Key words Inflammation - Intimal hyperplasia ·

Leukotriene receptors $\cdot$ Lipoxygenase $\cdot$ Myocardial infarction

\section{Bäck $(\square)$}

INSERM U698, Bichat Hospital,

46 rue Henri Huchard,

75018 Paris, France

e-mail: Magnus.Back@ki.se

M. Bäck

Center for Molecular Medicine, Karolinska University Hospital, L8:03,

17176 Stockholm, Sweden

\section{Leukotriene biosynthesis from phospholipids}

The proinflammatory lipid mediators known as the leukotrienes (LTs) were initially described by their bioactivity referred to as Slow Reacting Substance of Anaphylaxis (SRS-A; [1]), which was discovered after challenge of animal lungs with snake venom [2]. This observation has subsequently been explained by LT synthesis induced by phospholipase $\mathrm{A}_{2}\left(\mathrm{PLA}_{2}\right)$, which is the major enzymatic component of snake venom. PLA $_{2}$ consists of several groups of both secretory and cytosolic forms [3]. The cytosolic $\mathrm{PLA}_{2}\left(\mathrm{cPLA}_{2}\right)$ displays a calcium-dependent activation, and has a specificity for phospholipids with arachidonic acid (AA) bound at the sn-2 position. It is the resulting liberation of AA, which provides the substrate for the formation of LTs (Fig. 1) [4]. The subsequent enzymatic step, lipoxygenation of AA by 5-lipoxygenase (5-LO) and its activating protein FLAP (Fig. 1), yields the unstable product $\mathrm{LTA}_{4}$ [4]. Subsequently, the LT synthesis follows two distinct pathways. Hydrolysis of $\mathrm{LTA}_{4}$ leads to formation of $\mathrm{LTB}_{4}$, a potent chemoattractant and leukocyte activator [5]. On the other arm of the pathway, $\mathrm{LTA}_{4}$ is conjugated with glutathione by the action of $\mathrm{LTC}_{4}$ synthase (Fig. 1). The latter enzymatic step leads to the formation of $\mathrm{LTC}_{4}, \mathrm{D}_{4}$ and $\mathrm{E}_{4}$ (collectively referred to as the cysteinylLTs) (Fig. 1), which have been associated with bronchoand vasoconstriction [5].

Although the major interest for $\mathrm{PLA}_{2}$ in the context of atherosclerosis has been focused on their effects on lipoproteins [6], the participation of $\mathrm{PLA}_{2}$ in leukotriene formation may result in additional proatherogenic signaling from this enzymatic pathway. While the effects of different $\mathrm{PLA}_{2}$ inhibitors on leukotriene biosynthesis today remains largely unknown, specific interventions within the LT 


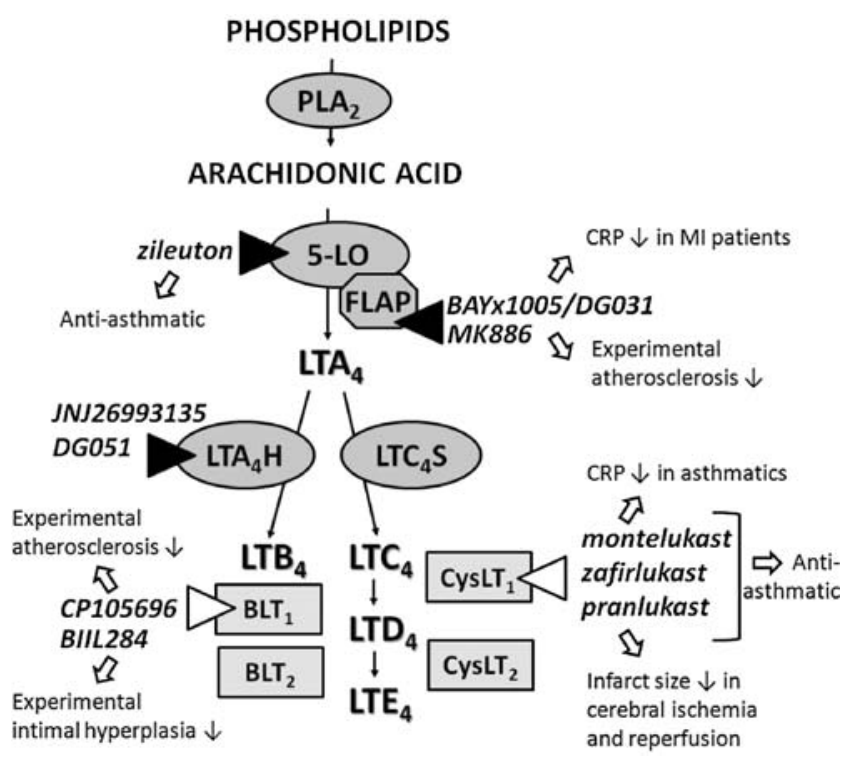

Fig. 1 The formation of leukotrienes (LTs) through the 5-lipoxygenase pathway of arachidonic acid metabolism, and the effects of LT inhibitors in different contexts. Gray ovals indicate the enzymes involved in LT biosynthesis; Phospholipase $\mathrm{A}_{2}\left(P L A_{2}\right)$, 5-lipoxygenase $(5-L O)$ with its activating protein $(F L A P)$, LTA 4 hydrolase $\left(L T A_{4} H\right)$, and $L T C_{4}$ synthase $\left(L T C_{4} S\right)$. Rectangles indicate the LT receptors. Examples of LT synthesis inhibitors are indicated by black triangles, whereas examples of LT receptor antagonists are indicated by open triangles

signaling have indicated beneficial effects on atherosclerosis development.

\section{Leukotriene receptors}

The biological actions of the LTs are transduced through 7transmembrane G-protein-coupled receptors (GPCR). The two arms of the LT pathway have distinct receptors referred to as BLT receptors (activated by $\mathrm{LTB}_{4}$ ) and CysLT receptors (activated by the cysteinyl-LTs), respectively (Fig. 1) [5]. While the BLT receptors are denoted BLT $_{1}$ and $\mathrm{BLT}_{2}$, for the high and low affinity receptor subtypes, respectively, receptors activated by the cysteinyl-LTs are characterized by their sensitivity to available antagonists and are referred to as $\mathrm{CysLT}_{1}$ and $\mathrm{CysLT}_{2}[7,8]$ The latter nomenclature probably only in part describes the cysteinylLT signaling, since limitation of the currently available CysLT receptor antagonists [8], as well as cross-reactivities between CysLT and purinoreceptors [9] indicate more complex receptor ligation properties for cysteinyl-LTs.

\section{Proinflammatory leukotriene signaling in atherosclerosis}

Although the use of statins may decrease both systemic and local inflammation in atherosclerosis, a potential further benefit could be anticipated by specific anti-inflammatory agents targeting key immune reactions in the atherosclerosis process. Ever since the concept of inflammation and atherosclerosis was raised, a number of inflammatory mediators has been explored as potential therapeutic targets in this disease [10]. The inflammatory response induced through LT signaling may be of particular interest in this context since several drugs targeting this pathway are either available or under development, as indicated in Fig. 1 [11]. Although there is a long tradition of treating asthma with anti-LTs [12], very little is known about the long term effects of the anti-asthmatic LT inhibitors on cardiovascular outcome. Some interesting indications can however be obtained from retrospective studies. For example, a randomized controlled trial of placebo versus either the $\mathrm{CysLT}_{1}$ receptor antagonist montelukast (Fig. 1) or theophylline, reported significantly lower levels of CRP in montelukast-treated patients with severe asthma [13]. Although no follow-up of those patients was performed in terms of cardiovascular disease, a systemic anti-inflammatory effect of montelukast could indicate potential beneficial effects.

Although asthma may not be a classical co-morbidity of atherosclerosis, LTs have been implicated as potential mediators of cardiovascular risk in other inflammatory diseases. For example, in studies of patients with chronic obstructive pulmonary disease (COPD), the prevalence of ischemic heart disease is approximately twofold higher compared with the general population [14]. The beneficial effects of anti-LTs in reducing air-flow obstruction in asthma has been reproduced in COPD patients [14]. Furthermore, short time treatment with the LT synthesis inhibitor BAYx1005/DG031 (Fig. 1) has been evaluated in both COPD and in patients with a history of myocardial infarction $[15,16]$. Although the treatment protocols used in both the latter two studies resulted in only modest inhibition of $\mathrm{LTB}_{4}$ concentrations in either sputum or stimulated whole blood, the results suggested a tendency for decrease of inflammatory markers $[15,16]$. Despite the limitations (small patient numbers, short time treatments, limited LT inhibition etc), these studies provide an initial suggestion as to a potential beneficial effect of an anti-LT treatment in atherosclerosis.

In addition to the lungs, the oral cavity may be another source of low grade chronic inflammation as a substrate for atherosclerosis development. Periodontal disease is for example associated with the development of early atherosclerotic lesions in the carotid artery [17], and an increased risk of stroke [18] and myocardial infarction [19]. The notion of LTs as common mediators of atherosclerosis and periodontal disease was recently suggested in a study associating high levels of cysteinyl-LTs in gingival crevicular fluid with an increased carotid artery wall thickness 
[20]. Chronic inflammation in the oral cavity can also be measured in the saliva, in which high LT concentrations have been demonstrated [21, 22], and reported to be inhibited by zileuton [23], an anti-asthmatic LT synthesis inhibitor (Fig. 1). Although hitherto not evaluated in the context of cardiovascular disease, those studies not only suggest the oral cavity as a site of chronic inflammation, but also indicate that the saliva may be a possible source for measures of LTs as biomarkers.

As a final example of co-morbidities in which LTs could act as a potential link to atherosclerosis, subjects with obstructive sleep apnea (OSA) exhibit significantly higher $\mathrm{LTB}_{4}$ synthesis in ex vivo stimulated neutrophils compared with control subjects [24]. Interestingly, the $\mathrm{LTB}_{4}$ production in subjects with OSA was significantly correlated to the carotid artery diameter in the latter study [24], further supporting the notion of LTs as potential mediators of the increased cardiovascular risk associated with different inflammatory conditions.

In addition to the studies implicating leukotrienes in comorbidities of atherosclerosis, studies of genetic polymorphisms have established significant associations for the LT pathway with early signs of atherosclerosis [25, 26], as well as the development of stroke and myocardial infarction $[27,28]$. Furthermore, mechanistic studies have implicated the LT pathway at several different stages of the atherosclerosis process (Fig. 2) [29]. For example, LT signaling has been suggested to be involved in the initiation of atherosclerosis, through both lipid retention and thickening of the vascular wall, as well as in the changes of the endothelial homeostasis that characterize early atherosclerosis (Fig. 2). Subsequently, the potent LT-induced immunostimulatory actions have indicated a key role in atheroma development. Furthermore, some studies have indicated a role for the LT pathway in plaque rupture, causing thrombosis and vessel occlusion (Fig. 2). The plaque rupture induces ischemia in distal organs, such as the brain and the myocardium, and the contribution of LT signaling in stroke and myocardial infarction has been studied in models of ischemia and reperfusion. Taken together, atherosclerotic processes deteriorating healthy vessels and causing organ damage may at each stage represent a putative target for anti-LT therapy. The next sections of this review will focus on how the LT pathway potentially may interact at those different stages of atherosclerosis development, and eventually its ischemic complication, such as myocardial infarction and stroke (Fig. 2).

\section{Lipid retention and modification}

The early sign of lipid retention within the vascular wall is referred to as fatty streaks, which appear early in life and may either disappear or develop into more advanced atherosclerotic lesions (Fig. 2) [10]. Fatty streaks consist mainly of lipid laden macrophages, or foam cells [10]. As lipids are taken up into the vascular wall, they undergo oxidative modifications [10]. Several studies support a lipoxygenase-mediated oxidation of low density lipoproteins (LDL) [30, 31], mainly mediated trough the 15lipoxygenase (15-LO) pathway [32]. However, recent findings have indicated an absence of 15-LO expression within atherosclerotic lesions [33], hence questioning its role as a driver of LDL oxidation in vivo. According to the latter study, 5-LO is the main lipoxygenase expressed within atherosclerotic lesions [33]. Since the role of 5-LO in LDL oxidations appears less convincing compared with the actions of $15-\mathrm{LO}[34,35]$, the atherogenic role of 5-LO may rather be dependent on its participation in the biosynthesis of LTs, and the pro-inflammatory signaling transduced through LT receptor activation [29]. The latter notion is supported by findings in atherosclerotic apolipo-

Fig. 2 The potential involvement of leukotrienes in the different stages of the atherosclerosis process eventually leading to cerebral and myocardial ischemia. Abbreviations: $S M C$ smooth muscle cells, MMP matrix metalloproteinase, $I / R$ ischemia and reperfusion

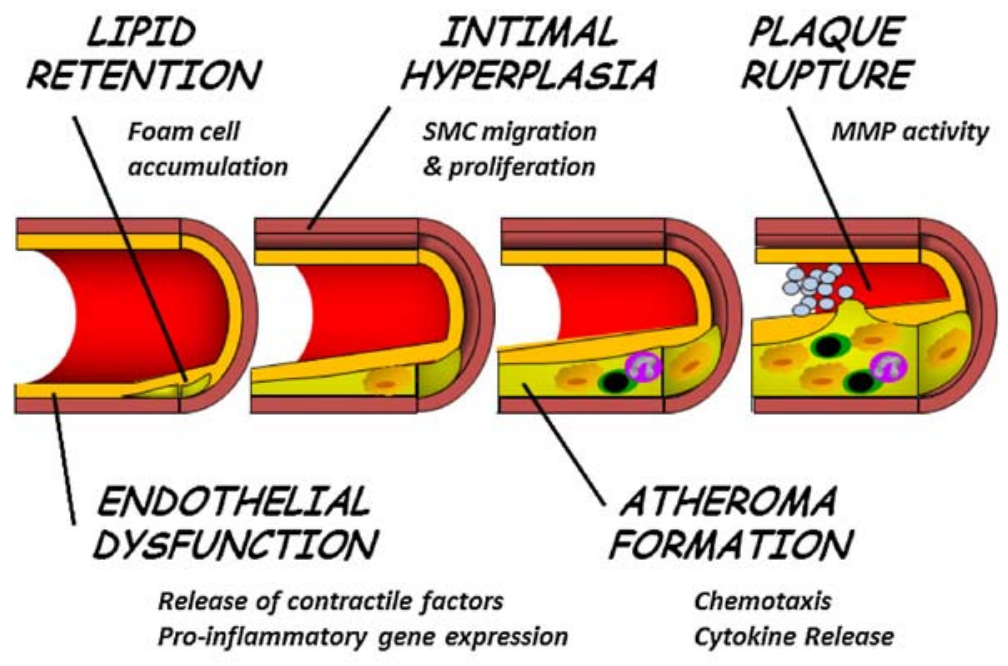

Pro-inflammatory gene expression

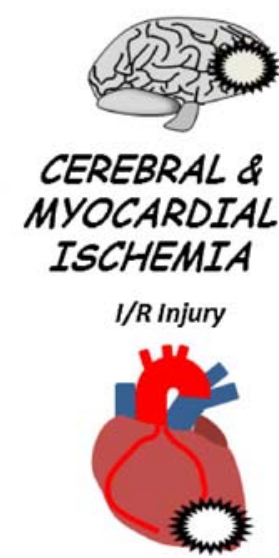


protein $\mathrm{E}$ (ApoE) knockout mice in which either genetic or pharmacological targeting of the $\mathrm{BLT}_{1}$ receptor reduces lipid accumulation and foam cell infiltration [36-38].

\section{Intimal hyperplasia}

Another sign of early atherosclerosis is the thickening of the inner muscular layer of the vascular wall, which is referred to as intimal hyperplasia (Fig. 2) [10]. CysteinylLT signaling through CysLT receptors mediates proliferation and migration of vascular smooth muscle cells (SMCs) [5]. In addition, the class of $\mathrm{CysLT}_{1}$ receptor antagonists used in the treatment of asthma (Fig. 1) inhibits intimal hyperplasia after vascular injury in different animal models $[5,39]$. Recently, it was discovered that SMCs within human atherosclerotic lesions also express receptors for $\mathrm{LTB}_{4}[38,40]$, mediating proliferation and migration of coronary artery SMCs [40]. The important signaling through these receptors has been supported by findings in $\mathrm{ApoE}^{-/-}$mice with a targeted $\mathrm{BLT}_{1}$ receptor, which have fewer SMCs in their lesions [38]. Furthermore, BLT receptor antagonism reduces intimal hyperplasia after vascular injury in rats $[5,40]$. Taken together, the LTinduced stimulation of SMCs suggests their involvement in the intimal hyperplasia associated both with early atherosclerosis and in-stent restenosis after coronary interventions [5].

\section{Endothelial dysfunction}

While in healthy individuals, the endothelium contributes to vascular homeostasis, atherosclerosis is characterized by a dysfunctional endothelium (Fig. 2). Cysteinyl-LT activation of endothelial cells have been reported to be transduced through constitutively expressed $\mathrm{CysLT}_{2}$ receptors [41, 42] coupled to a release of relaxant factors [5]. However, while a proinflammatory environment down-regulates CysLT $_{2}$ receptor expression in human umbilical vein endothelial cells (HUVECs) [42], CysLT 1 receptor expression is induced in HUVECs under such conditions [43]. Furthermore, studies of isolated arteries have demonstrated endothelium-dependent contractions through $\mathrm{CysLT}_{1}$ receptor signaling [44, 45]. Taken together, those observations suggest that a balance of CysLT receptor subtype expression may determine the LT-induced endothelium-dependent vasomotor responses. The latter notion has in addition received support from animal models. Directed endothelial expression of the human $\mathrm{CysLT}_{2}$ receptor in mice induces an enhanced $\mathrm{NO}$ production in response to $\mathrm{LTC}_{4}$, but does not change baseline systemic blood pressure compared with wild type mice [46]. Furthermore, although the LT synthesis inhibitor MK-886 (Fig. 1) does not alter mean arterial blood pressure in spontaneously hypertensive rats [47], this treatment prevents the rise in blood pressure observed in rats chronically treated by an NO synthesis inhibitor [48]. In summary, data from several studies using different in vivo and in vitro models suggest that cysteinyl-LT signaling may provide a key balance between a release of endothelium-dependent relaxant and constricting factors.

In contrast to this relatively extensive exploration of CysLT receptor signaling on endothelial cells, less is known about the signaling of the other arm of the LT pathway, through BLT receptors, in this context. Although healthy human arteries may not express receptors for $\mathrm{LTB}_{4}$, an endothelial $\mathrm{BLT}_{1}$ receptor expression is induced in atherosclerotic lesions [40]. Findings in animal models have in addition suggested that $\mathrm{LTB}_{4}$-signaling through the $\mathrm{BLT}_{1}$ receptor may also be associated with an endotheliumdependent release of vasoactive factors [49, 50].

In addition to direct action on the vascular tone, LTinduced activation of endothelial cells may also lead to changes in the transcriptional activity. In HUVECs, $\mathrm{LTD}_{4}$ induces endothelial P-selectin expression through $\mathrm{CysLT}_{2}$ receptor activation [51]. Furthermore, the $\mathrm{CXC}$ chemokines CXCL-2 [52] and IL-8 [53] are found among the most upregulated genes after stimulation of HUVECs with $\mathrm{LTD}_{4}$. The latter findings suggest that LT-induced activation of the endothelium in addition may participate in the starting point of the immune activation associated with the atheroma formation.

\section{Atherosclerotic plaque formation}

Foam cell accumulation and altered endothelial homeostasis will induce progressive recruitment of different populations of immune cells to the vascular wall, and eventually lead to the formation of the atherosclerorotic plaque, or atheroma (Fig. 2) [10]. This process is characterized not only by a reduction of the arterial lumen size, but also by the formation of a necrotic lipid core surrounded by a fibrous cap of extracellular matrix and SMCs (Fig. 2) [10]. The chemoattractant activity induced by $\mathrm{LTB}_{4}$ through $\mathrm{BLT}_{1}$ and $\mathrm{BLT}_{2}$ receptors expressed on monocytes may play an important role in the continued accumulation of macrophages at the site of the initial foam cell infiltration [36]. Since macrophages represent a major source of 5-LO in the cardiovascular system, $\mathrm{LTB}_{4}$-induced monocyte recruitment could potentially further exacerbate the inflammatory activity at sites of atherosclerotic lesions. Furthermore, $\mathrm{LTB}_{4}$ also induces chemotaxis of other immune cells, such as Tlymphocytes, which accumulate in the vicinity of 5-LOpositive macrophages [52]. In a mouse model combining hyperinflammation and hyperlipidemia, through selective 
abrogation of T-cell TGF $\beta$ signaling in $\mathrm{ApoE}^{-/-}$mice, a stimulatory effect of activated T-lymphocytes on LT synthesis has been demonstrated [54]. Activated T-lymphocytes upregulate the expression of FLAP in macrophages, leading to an increased $\mathrm{LTB}_{4}$ formation [54]. The increased $\mathrm{LTB}_{4}$ formation that results from both monocyte recruitment and T-lymphocyte-mediated FLAP up-regulation, may lead to a vicious circle involving progressive recruitment of inflammatory cells and a maintained immune activation within the atherosclerotic lesion [29, 54]. Selective targeting of $\mathrm{LTB}_{4}$ signaling could be key in blocking this vicious circle, as suggested by the capacity of different anti-leukotriene treatment strategies to reduce atheroma macrophage and Tlymphocyte content in hyperlipidemic mice (Fig. 1) [29].

\section{Plaque rupture}

Rupture of the fibrous cap will expose the content of the atheroma to the circulation, leading to platelet activation and thrombotic occlusion of the arterial lumen [10]. In a coronary artery, this process will lead to myocardial ischemia whereas in the cerbrovasculature, cerebral ischemia will occur (Fig. 2). The role of leukotrienes in plaque rupture has been suggested through transcriptional profiling of carotid endarterectomies, in which the constituents of the leukotriene pathway are expressed at higher levels in specimens obtained from patients with recent clinical signs of cerebral ischemia compared with asymptomatic patients [55]. One of the key components in plaque instability and rupture is the degradation of extracellular matrix by specific matrix metalloproteinases (MMPs) [56]. The production, secretion and activation of MMPs may be dependent on the generation of endogenous LTs, as suggested by the co-localization of 5-LO with MMPs in human carotid atherosclerotic lesions [55]. The latter observation was recently extended to endarterectomies derived from diabetic patients, in which 5-LO expression and $\mathrm{LTB}_{4}$ production was associated with increased levels of MMP protein [57]. Furthermore, smokers exhibit a significant correlation between $\mathrm{LTB}_{4}$ concentrations and MMP-9 activity in saliva [21]. Taken together, those studies suggest that both LTs and MMPs are simultaneously increased during an inflammatory response.

Those observations provide an initial suggestion of inhibited protease activities after pharmacological inhibition of LT signaling, with potential therapeutic implications for the prevention of plaque rupture.

\section{Myocardial ischemia}

In support of a link between leukotrienes and coronary plaque rupture, increased levels of urinary LTs have been reported in patients with acute coronary syndromes [58]. However, whether urinary LTs are markers of plaque rupture, or rather reflects the inflammatory response associated with myocardial ischemia remains to be established. Experimental myocardial ischemia indeed induces increased LT production [59, 60]. Several studies of transient ischemia in isolated perfused hearts derived from either rats or rabbits have in addition indicated an improved myocardial recovery after LT inhibition [59-62]. However, the results of in vivo ischemia and reperfusion have provided contradictory results. Either CysLT $_{1}$ receptor antagonism or LT synthesis inhibition induces a protective effect after myocardial ischemia followed by reperfusion in rabbits and cats, respectively [60, 63]. In contrast, different LT receptor antagonists have been reported not to alter the infarct size after myocardial ischemia and reperfusion in rats $[61,64]$, and both positive and neutral effects have been reported for LT synthesis inhibitors in dogs $[65,66]$. In mice subjected to coronary ligation and reperfusion, the infarct size is not affected by either 5-LO knock out or CysLT receptor antagonism [67, 68]. In the latter model, 5-LO deficient mice have been reported to exhibit an even increased neutrophil infiltration and proinflammatory gene expression within the infarction area compared with wild type mice [67]. Although the these results raise a doubt as to the role of LTs in myocardial ischemia, a recent study of transgenic mice expressing a human endothelial $\mathrm{CysLT}_{2}$ receptor, have reported an increased infarct size and leukocyte infiltration resulting from signaling trough this receptor [67]. However, the absence of atherosclerosis in the latter studies may limit the extrapolation of the findings to human coronary syndromes. As discussed above, the endothelial $\mathrm{CysLT}_{2}$ receptor is rapidly down-regulated by pro-inflammatory stimuli in vitro [42]. Furthermore, microcirculatory changes induced during atherosclerosis have in addition been suggested by the exaggerated leukocyte recruitment and plasma leakage after ischemia and reperfusion in hypercholesterolemic $\mathrm{LDLR}^{-/}$ mice [69]. Although a role for LTs in this enhanced response was not established in the latter study [69], the LTB $_{4}$-induced leukocyte adhesion and migration, as determined by intravital microscopy in postcapillary venules, are significantly enhanced in $\mathrm{LDLR}^{-/-}$compared with wild type mice [70].

\section{Cerebral ischemia}

The notion of LT production in the ischemic brain was firstly raised by studies in gerbils [71], in which inhibitors of LT synthesis limit the damage after transient cerebral ischemia [72]. Subsequent studies in rats have associated beneficial effects with the cysteinyl-LT arm of the AA metabolism. For example, anti-asthmatic $\mathrm{CysLT}_{1}$ receptor antagonists, such as pranlukast and montelukast, reduce the effects of both focal 
and global ischemia provoked through either transient or permanent cerebral artery occlusion in rats [9, 73, 74] (Fig. 1). Interestingly, a purino-like GPRC named GPR17 has been shown to in addition to uracil nucleotides, also be activated by $\mathrm{LTD}_{4}$ and $\mathrm{LTC}_{4}$ [9]. This potentially dual CysLT and purinoreceptor is up-regulated in the ischemic brain, and silenced receptor expression in vivo mimics the neuroprotective effects of montelukast after $48 \mathrm{~h}$ of permanent focal ischemia.

\section{Conclusion}

The proinflammatory signaling induced by LT receptor ligation has been implicated at several stages of the atherosclerosis process, and may represent a putative target in the design of novel anti-inflammatory strategies to prevent myocardial infarction and stroke. Based on findings in different animal models of atherosclerosis [29], beneficial effects could be anticipated by anti-LT treatments. Although some findings in humans based on either genetic associations [25-28] or LT measurements in different patient populations $[20,21,24,58]$, support this notion, it may currently be premature to conclude on what exact mechanisms to target in human disease. Some interesting information can however be obtained through studies of other pathologies in which anti-LT treatments already have been evaluated $[12,14]$. In the latter context, the effects of LT inhibition is of particular interest in the context of diseases associated with an increased cardiovascular risk, such as COPD and periodontitis [14, 20]. The challenge is now to extrapolate experimental findings to a clinical setting in order to identify patients groups that would benefit from an inhibited LT signaling.

Acknowledgements The author is supported by the French National Academy of Medicine, the French-Swedish Foundation, the Leducq Transatlantic Network of Excellence on Atherothrombosis Research, the Swedish Heart and Lung Foundation, the CMM-Söderberg Foundation and the Karolinska Institutet Respiration and Circulation Network (KIRCNet).

Open Access This article is distributed under the terms of the Creative Commons Attribution Noncommercial License which permits any noncommercial use, distribution, and reproduction in any medium, provided the original author(s) and source are credited.

\section{References}

1. Brocklehurst WE. The release of histamine and formation of a slow-reacting substance (SRS-A) during anaphylactic shock. J Physiol. 1960;151:416-35.

2. Feldberg W, Kellaway $\mathrm{CH}$. Liberation of histamine and formation of lysocithin-like substances by cobra venom. J Physiol. 1938;94:187-226.
3. Schaloske RH, Dennis EA. The phospholipase A2 superfamily and its group numbering system. Biochim Biophys Acta. 2006; 1761:1246-59.

4. Peters-Golden M, Henderson WR Jr. Leukotrienes. N Engl J Med. 2007;357:1841-54.

5. Bäck M. Leukotriene receptors: crucial components in vascular inflammation. ScientificWorldJournal. 2007;7:1422-39.

6. Rosenson RS. Fenofibrate reduces lipoprotein associated phospholipase A2 mass and oxidative lipids in hypertriglyceridemic subjects with the metabolic syndrome. Am Heart J. 2008;155:499 9-16.

7. Brink C, Dahlen SE, Drazen J, Evans JF, Hay DW, Nicosia S, et al. International Union of Pharmacology XXXVII. Nomenclature for leukotriene and lipoxin receptors. Pharmacol Rev. 2003; 55:195-227.

8. Bäck M. Functional characteristics of cysteinyl-leukotriene receptor subtypes. Life Sci. 2002;71:611-22.

9. Ciana P, Fumagalli M, Trincavelli ML, Verderio C, Rosa P, Lecca $\mathrm{D}$, et al. The orphan receptor GPR17 identified as a new dual uracil nucleotides/cysteinyl-leukotrienes receptor. EMBO J. 2006;25:4615-27.

10. Hansson GK. Inflammation, atherosclerosis, and coronary artery disease. N Engl J Med. 2005;352:1685-95.

11. Whatling $\mathrm{C}, \mathrm{McPheat} \mathrm{W}$, Herslöf M. The potential link between atherosclerosis and the 5-lipoxygenase pathway: investigational agents with new implications for the cardiovascular field. Expert Opin Investig Drugs. 2007;16:1879-93.

12. Dahlén SE. Treatment of asthma with antileukotrienes: First line or last resort therapy? Eur J Pharmacol. 2006;533:40-56.

13. Allayee H, Hartiala J, Lee W, Mehrabian M, Irvin CG, Conti DV, et al. The effect of montelukast and low-dose theophylline on cardiovascular disease risk factors in asthmatics. Chest 2007; 132:868-74.

14. Bäck M. Atherosclerosis, COPD and chronic inflammation. Resp Med COPD Update. 2008;4:60-5.

15. Gompertz S, Stockley RA. A randomized, placebo-controlled trial of a leukotriene synthesis inhibitor in patients with COPD. Chest 2002;122:289-94.

16. Hakonarson H, Thorvaldsson S, Helgadottir A, Gudbjartsson D, Zink F, Andresdottir M, et al. Effects of a 5-lipoxygenase-activating protein inhibitor on biomarkers associated with risk of myocardial infarction: a randomized trial. JAMA 2005;293:2245-56.

17. Söder PÖ, Söder B, Nowak J, Jogestrand T. Early carotid atherosclerosis in subjects with periodontal disease. Stroke 2005;36:1195-200.

18. Grau AJ, Becher H, Ziegler CM, Lichy C, Buggle F, Kaiser C, et al. Periodontal disease as a risk factor for ischemic stroke. Stroke 2004;35:496-501.

19. Persson R, Ohlsson O, Pettersson T, Renvert S. Chronic periodontitis, a significant relationship with acute myocardial infarction. Eur Heart J. 2003;24:2108-15.

20. Bäck M, Airila-Månsson S, Jogestrand T, Söder B, Söder PO. Increased leukotriene concentrations in gingival crevicular fluid from subjects with periodontal disease and atherosclerosis. Atherosclerosis 2007;193:389-94.

21. Bäck M, Hlawaty H, Labat C, Michel JB, Brink C. The oral cavity and age: a site of chronic inflammation? PLoS One. 2007;2:e1351.

22. Gaber F, Acevedo F, Delin I, Sundblad B, Palmberg L, Larsson K, et al. Saliva is one likely source of leukotriene B4 in exhaled breath condensate. Eur Respir J. 2006;28:1229-35.

23. Gaber F, James A, Delin I, Wetterholm A, Sampson AP, Dahlen B, et al. Assessment of in vivo 5-lipoxygenase activity by analysis of leukotriene B4 in saliva: effects of treatment with zileuton. J Allergy Clin Immunol. 2007;119:1267-8.

24. Lefebvre B, Pepin JL, Baguet JP, Tamisier R, Roustit M, Riedweg $\mathrm{K}$, et al. Leukotriene B4: early mediator of atherosclerosis in obstructive sleep apnoea? Eur Respir J. 2008;32:113-20. 
25. Dwyer JH, Allayee H, Dwyer KM, Fan J, Wu H, Mar R, et al. Arachidonate 5-lipoxygenase promoter genotype, dietary arachidonic acid, and atherosclerosis. N Engl J Med. 2004;350:29-37.

26. Iovannisci DM, Lammer EJ, Steiner L, Cheng S, Mahoney LT, Davis $\mathrm{PH}$, et al. Association between a leukotriene $\mathrm{C} 4$ synthase gene promoter polymorphism and coronary artery calcium in young women: the Muscatine Study. Arterioscler Thromb Vasc Biol. 2007;27:394-9.

27. Helgadottir A, Manolescu A, Thorleifsson G, Gretarsdottir S, Jonsdottir H, Thorsteinsdottir U, et al. The gene encoding 5lipoxygenase activating protein confers risk of myocardial infarction and stroke. Nat Genet. 2004;36:233-9.

28. Freiberg JJ, Tybjaerg-Hansen A, Sillesen H, Jensen GB, Nordestgaard BG. Promotor polymorphisms in leukotriene C4 synthase and risk of ischemic cerebrovascular disease. Arterioscler Thromb Vasc Biol. 2008;28:990-6.

29. Bäck M. Inflammatory signaling through leukotriene receptors in atherosclerosis. Curr Atheroscler Rep. 2008;10:244-51.

30. Sparrow CP, Parthasarathy S, Steinberg D. Enzymatic modification of low density lipoprotein by purified lipoxygenase plus phospholipase A2 mimics cell-mediated oxidative modification. J Lipid Res. 1988;29:745-53.

31. Parthasarathy S, Wieland E, Steinberg D. A role for endothelial cell lipoxygenase in the oxidative modification of low density lipoprotein. Proc Natl Acad Sci U S A. 1989;86:1046-50.

32. Folcik VA, Nivar-Aristy RA, Krajewski LP, Cathcart MK. Lipoxygenase contributes to the oxidation of lipids in human atherosclerotic plaques. J Clin Invest. 1995;96:504-10.

33. Spanbroek R, Gräbner R, Lötzer K, Hildner M, Urbach A, Rühling $\mathrm{K}$, et al. Expanding expression of the 5-lipoxygenase pathway within the arterial wall during human atherogenesis. Proc Natl Acad Sci U S A. 2003;100:1238-43.

34. Jessup W, Darley-Usmar V, O'Leary V, Bedwell S. 5-Lipoxygenase is not essential in macrophage-mediated oxidation of lowdensity lipoprotein. Biochem J. 1991;278:163-9.

35. Folcik VA, Cathcart MK. Assessment of 5-lipoxygenase involvement in human monocyte-mediated LDL oxidation. J Lipid Res. 1993;34:69-79.

36. Aiello RJ, Bourassa PA, Lindsey S, Weng W, Freeman A, Showell HJ. Leukotriene B4 receptor antagonism reduces monocytic foam cells in mice. Arterioscler Thromb Vasc Biol. 2002;22:443-9.

37. Subbarao K, Jala VR, Mathis S, Suttles J, Zacharias W, Ahamed J, et al. Role of leukotriene B4 receptors in the development of atherosclerosis: potential mechanisms. Arterioscler Thromb Vasc Biol. 2004;24:369-75.

38. Heller EA, Liu E, Tager AM, Sinha S, Roberts JD, Koehn SL, et al. Inhibition of atherogenesis in BLT1-deficient mice reveals a role for LTB4 and BLT1 in smooth muscle cell recruitment. Circulation 2005;112:578-86.

39. Kaetsu Y, Yamamoto Y, Sugihara S, Matsuura T, Igawa G, Matsubara K, et al. Role of cysteinyl leukotrienes in the proliferation and the migration of murine vascular smooth muscle cells in vivo and in vitro. Cardiovasc Res. 2007;76:160-6.

40. Bäck M, Bu DX, Bränstrom R, Sheikine Y, Yan ZQ, Hansson GK. Leukotriene B4 signaling through NF-kappaB-dependent BLT1 receptors on vascular smooth muscle cells in atherosclerosis and intimal hyperplasia. Proc Natl Acad Sci U S A. 2005;102:17501-6.

41. Mita H, Hasegawa M, Saito H, Akiyama K. Levels of cysteinyl leukotriene receptor mRNA in human peripheral leucocytes: significantly higher expression of cysteinyl leukotriene receptor 2 mRNA in eosinophils. Clin Exp Allergy. 2001;31:1714-23.

42. Lotzer K, Spanbroek R, Hildner M, Urbach A, Heller R, Bretschneider E, et al. Differential leukotriene receptor expression and calcium responses in endothelial cells and macrophages indicate 5-lipoxygenase-dependent circuits of inflammation and atherogenesis. Arterioscler Thromb Vasc Biol. 2003;23:e32-6.
43. Gronert K, Martinsson-Niskanen T, Ravasi S, Chiang N, Serhan $\mathrm{CN}$. Selectivity of recombinant human leukotriene $\mathrm{D}(4)$, leukotriene $\mathrm{B}(4)$, and lipoxin $\mathrm{A}(4)$ receptors with aspirin-triggered 15-epiLXA(4) and regulation of vascular and inflammatory responses. Am J Pathol. 2001;158:3-9.

44. Ortiz JL, Gorenne I, Cortijo J, Seller A, Labat C, Sarria B, et al. Leukotriene receptors on human pulmonary vascular endothelium. Br J Pharmacol. 1995;115:1382-6.

45. Bäck M, Norel X, Walch L, Gascard J, Mazmanian G, Dahlén S, et al. Antagonist resistant contractions of the porcine pulmonary artery by cysteinyl-leukotrienes. Eur J Pharmacol. 2000;401:381-8.

46. Hui Y, Cheng Y, Smalera I, Jian W, Goldhahn L, Fitzgerald GA, et al. Directed vascular expression of human cysteinyl leukotriene 2 receptor modulates endothelial permeability and systemic blood pressure. Circulation 2004;110:3360-6.

47. Lefebvre B, Caron F, Bessard G, Stanke-Labesque F. Effect of 5lipoxygenase blockade on blood pressure and acetylcholineevoked endothelium-dependent contraction in aorta from spontaneously hypertensive rats. J Hypertens. 2006;24:85-93.

48. Stanke-Labesque F, Hardy G, Caron F, Cracowski JL, Bessard G. Inhibition of leukotriene synthesis with MK-886 prevents a rise in blood pressure and reduces noradrenaline-evoked contraction in L-NAME-treated rats. Br J Pharmacol. 2003;140:186-94.

49. Bäck M, Qiu H, Haeggstrom JZ, Sakata K. Leukotriene B4 is an indirectly acting vasoconstrictor in guinea pig aorta via an inducible type of BLT receptor. Am J Physiol Heart Circ Physiol. 2004;287:H419-24.

50. Bäck M, Sakata K, Qiu H, Haeggstrom JZ, Dahlén S. Endothelium-dependent vascular responses induced by leukotriene B4. Prostaglandins Other Lipid Mediat. 2007;83:209-12.

51. Pedersen KE, Bochner BS, Undem BJ. Cysteinyl leukotrienes induce P-selectin expression in human endothelial cells via a nonCysLT1 receptor-mediated mechanism. J Pharmacol Exp Ther. 1997;281:655-62.

52. Zhao L, Moos MP, Grabner R, Pedrono F, Fan J, Kaiser B, et al. The 5-lipoxygenase pathway promotes pathogenesis of hyperlipidemia-dependent aortic aneurysm. Nat Med. 2004;10:966-73.

53. Uzonyi B, Lotzer K, Jahn S, Kramer C, Hildner M, Bretschneider E, et al. Cysteinyl leukotriene 2 receptor and protease-activated receptor 1 activate strongly correlated early genes in human endothelial cells. Proc Natl Acad Sci U S A. 2006;103:6326-31.

54. Bäck M, Sultan A, Ovchinnikova O, Hansson GK. 5-Lipoxygenase-activating protein: a potential link between innate and adaptive immunity in atherosclerosis and adipose tissue inflammation. Circ Res. 2007;100:946-9.

55. Cipollone F, Mezzetti A, Fazia ML, Cuccurullo C, Iezzi A, Ucchino S, et al. Association between 5-lipoxygenase expression and plaque instability in humans. Arterioscler Thromb Vasc Biol. $2005 ; 25: 1665-70$.

56. Newby AC. Dual role of matrix metalloproteinases (matrixins) in intimal thickening and atherosclerotic plaque rupture. Physiol Rev. 2005;85:1-31.

57. Zhou YJ, Wang JH, Li L, Yang HW, Wen de L, He QC. Expanding expression of the 5-lipoxygenase/leukotriene B4 pathway in atherosclerotic lesions of diabetic patients promotes plaque instability. Biochem Biophys Res Commun. 2007;363:30-6.

58. Carry M, Korley V, Willerson JT, Weigelt L, Ford-Hutchinson AW, Tagari P. Increased urinary leukotriene excretion in patients with cardiac ischemia. In vivo evidence for 5-lipoxygenase activation. Circulation 1992;85:230-6.

59. Lee CC, Appleyard RF, Byrne JG, Cohn LH. Leukotrienes D4 and $\mathrm{E} 4$ produced in myocardium impair coronary flow and ventricular function after two hours of global ischaemia in rat heart. Cardiovasc Res. 1993;27:770-3.

60. Rossoni G, Sala A, Berti F, Testa T, Buccellati C, Molta C, et al. Myocardial protection by the leukotriene synthesis inhibitor BAY 
X1005: importance of transcellular biosynthesis of cysteinylleukotrienes. J Pharmacol Exp Ther. 1996;276:335-41.

61. Shekher A, Singh M. Role of eicosanoid inhibition of ischemia reperfusion injury: intact and isolated rat heart studies. Methods Find Exp Clin Pharmacol. 1997;19:223-9.

62. Semb AG, Vaage J, Mjos OD. Oxygen free radical producing leukocytes cause functional depression of isolated rat hearts: role of leukotrienes. J Mol Cell Cardiol. 1990;22:555-63.

63. Hock CE, Beck LD, Papa LA. Peptide leukotriene receptor antagonism in myocardial ischaemia and reperfusion. Cardiovasc Res. 1992;26:1206-11.

64. Egan JW, Griswold DE, Hillegass LM, Newton JF, Eckardt RD, Slivjak MJ, et al. Selective antagonism of peptidoleukotriene responses does not reduce myocardial damage or neutrophil accumulation following coronary artery occlusion with reperfusion. Prostaglandins 1989;37:597-613.

65. Mullane K, Hatala MA, Kraemer R, Sessa W, Westlin W. Myocardial salvage induced by REV-5901: an inhibitor and antagonist of the leukotrienes. J Cardiovasc Pharmacol. 1987;10:398-406.

66. Hahn RA, MacDonald BR, Simpson PJ, Potts BD, Parli CJ. Antagonism of leukotriene B4 receptors does not limit canine myocardial infarct size. J Pharmacol Exp Ther. 1990;253:58-66.

67. Adamek A, Jung S, Dienesch C, Laser M, Ertl G, Bauersachs J, et al. Role of 5-lipoxygenase in myocardial ischemia-reperfusion injury in mice. Eur J Pharmacol. 2007;571:51-4.
68. Jiang W, Hall SR, Moos MP, Cao RY, Ishii S, Ogunyankin KO, et al. Endothelial cysteinyl leukotriene 2 receptor expression mediates myocardial ischemia-reperfusion injury. Am J Pathol. 2008;172:592-602.

69. Mori N, Horie Y, Gerritsen ME, Granger DN. Ischemia-reperfusion induced microvascular responses in LDL-receptor $-/-$ mice. Am J Physiol. 1999;276:H1647-54.

70. Henninger DD, Gerritsen ME, Granger DN. Low-density lipoprotein receptor knockout mice exhibit exaggerated microvascular responses to inflammatory stimuli. Circ Res. 1997;81: 274-81.

71. Moskowitz MA, Kiwak KJ, Hekimian K, Levine L. Synthesis of compounds with properties of leukotrienes C4 and D4 in gerbil brains after ischemia and reperfusion. Science 1984; 224:886-9.

72. Rao AM, Hatcher JF, Kindy MS, Dempsey RJ. Arachidonic acid and leukotriene C4: role in transient cerebral ischemia of gerbils. Neurochem Res. 1999;24:1225-32.

73. Zhang LH, Wei EQ. Neuroprotective effect of ONO-1078, a leukotriene receptor antagonist, on transient global cerebral ischemia in rats. Acta Pharmacol Sin. 2003;24:1241-7.

74. Fang SH, Wei EQ, Zhou Y, Wang ML, Zhang WP, Yu GL, et al. Increased expression of cysteinyl leukotriene receptor-1 in the brain mediates neuronal damage and astrogliosis after focal cerebral ischemia in rats. Neuroscience 2006;140:969-79. 